\title{
Preparation and Application of a Xylan-based Antibacterial Papermaking Additive to Protect Against Escherichia coli Bacteria
}

\begin{abstract}
Guibin $\mathrm{Xu},{ }^{\mathrm{a}}$ Yuanchao Luo, ${ }^{\mathrm{a}}$ Tao Song, ${ }^{\mathrm{a}, *}$ Bei He, ${ }^{\mathrm{a}}$ Minmin Chang, ${ }^{\mathrm{a}}$ and Junli Ren ${ }^{\mathrm{b}, *}$
A xylan-based antimicrobial additive agent was prepared and studied for use in paper products against Escherichia coli bacteria. The derived cationic-xylan-grafted-guanidine polymer (CX-g-PHGH) was successfully synthesized by graft copolymerization of cationic-xylan with polyhexamethylene guanidine hydrochloride (PHGH) using ceric ammonium nitrate as an initiator. The obtained $\mathrm{CX}-\mathrm{g}-\mathrm{PHGH}$ had a maximum $\mathrm{PHGH}$ grafting ratio of $18.4 \%$ and efficiency of $58.4 \%$ and showed good viscosity and thermal stability. Furthermore, the paper samples prepared in this work were reinforced noticeably with the addition of CX-g-PHGH, after which exhibited improved mechanical properties. Compared to the reference paper without any of the xylan derivatives, the index of tensile, tear, burst, and folding endurance of the paper were increased by up to $20.1 \%, 25.3 \%$, $30.2 \%$, and $77.8 \%$, respectively. Moreover, the prepared CX-g-PHGH paper exhibited efficient antimicrobial barrier properties against $E$. coli bacteria, by which many applications based on the new xylan derived additive agent obtained in this work could be found, especially in field of antimicrobial paper products against $E$. coli bacteria from contaminated food.
\end{abstract}

Keywords: Antimicrobial additive agent; Cationic xylan; Escherichia coli; Mechanical properties; Paper products; $\mathrm{PHGH}$; Thermal stability

Contact information: a: State Key Laboratory of Pulp and Paper Engineering, South China University of Technology, Guangzhou, 510640, China; b: School of Light Industry and Engineering, South China

University of Technology, Guangzhou, 510340, China;

*Corresponding authors: songt@scut.edu.cn; renjunli@scut.edu.cn

\section{INTRODUCTION}

For a long time, the control of harmful bacterial infection has received significant attention, especially with the increasing demand for quality of living environments and working conditions in today's society (Yang et al. 2019). Pathogenic Escherichia coli are naturally occurring bacteria found in the environment, foods, and mostly in intestines of people and animals. E. coli is a common zoonotic bacterial pathogen and is an associated cause of a variety of intestinal and extraintestinal diseases, such as diarrhea, urinary tract infections, septicemia, neonatal meningitis, and other illnesses (Kim 2003; Conrad et al. 2014; Wang et al. 2016; Karmali 2017; Liu et al. 2018) The contamination of food, specifically meat, with pathogenic $E$. coli can occur during evisceration and harvesting of the meat, making it one of the most common causes of food-borne diseases (Lin et al. 2019; Manage et al. 2019). Moreover, contact of pathogenic E. coli to the human body via different kinds of residing platforms, such as food-related paper products, e.g. packaging paper, baking paper, napkin paper, pulp molded tableware, etc., is also a common pathway that can lead to human health problems. Therefore, using antimicrobial products for food- 
related applications is one of the most efficient and popular ways to reduce the risk of infection from daily eating habits.

Antimicrobial products based on various raw materials after modification have been extensively studied in the world (Shaer et al. 2012; Poverenov et al. 2013; Demetrescu et al. 2018; Diaz-García et al. 2019). Especially in recent years, antimicrobial products based on biological macromolecules from biomass including lignin, pectin, and different kinds of polysaccharides (e.g., cellulose, starch, and hemicellulose) have gained increasing interest due to many superior properties of these kinds of macromolecules such as biodegradability, good biocompatibility, good bioactivity, a wide range of resources from which to make the product, and easy modification of the end product (Guan et al. 2008; Dutta et al. 2009; Kang et al. 2013). For instance, composites of silvernanoparticles/bacterial-cellulose exhibited significant antibacterial activities against $E$. coli and other bacteria (Wu et al. 2014). Antimicrobial nanostructured films based on starch demonstrate antimicrobial activity against Staphylococcus aureus and other bacteria (Abreu et al. 2015).

Food-related cellulosic products, such as food packaging paper, baking paper, and napkin paper, are important products in daily life due to many superior properties of them such as their light weight, ease of modification and use, renewability, and biodegradability. However, cellulosic products naturally do not have any antimicrobial properties. Therefore, bacteria can multiply rapidly in the cellulosic products if proper conditions are fulfilled. Therefore, there have been many different kinds of natural and synthetic polymers or materials widely studied and used as antibacterial additive agents on these paper products (Qian et al. 2008, 2011a,b; Sun et al. 2010). The addition of antimicrobial agents, especially the agents based on biodegradable biomass on the paper products, is a promising way to efficiently and sustainably introduce antimicrobial properties to the required materials.

Xylan is the next highest naturally occurring biomolecule in the plant world after cellulose and possibly lignin. It is the most common polysaccharide in angiosperms, grasses, and cereals, where it exists in different compositions and structures (Ebringerová and Heinze 2015). The content of xylan varies in different species, but it constitutes up to $35 \%$ in sugarcane bagasse and 50\% in straws (Zyl et al. 1988; Sun 2010). Similar to cellulose, xylan is also a polyhydroxyl carbohydrate polymer with xylose as a main sugar unit linked by glycosidic bonds and functioning as support material in the cell wall (Horton 1968). Xylan is readily available from pulp refining and cereal processing industries, and is at the same time environmentally friendly, renewable, sustainable, biodegradable, and biocompatible. Xylan has been found to have many potential applications in food, papermaking, textile, plastic industries, and biomedical applications (Hromádková et al. 1999; Ünlü et al. 2009; Li et al. 2011). Moreover, xylan also has great potential to be applied as an antimicrobial material after modification and has received increasing attention from the international community. Recently, the importance of xylan-based macromolecules (Schwikal et al. 2005; Petzold et al. 2006; Ren et al. 2007, 2008) and materials (Lindblad et al. 2001; Goksu et al. 2007; Hansen and Plackett 2008) has obtained increasing focus, including the antimicrobial modification of xylan used in the field of film packaging, food preservation, as well as in biomedical areas (Wang et al. 2010; Melosilveira et al. 2011; Pristov et al. 2011; Ren et al. 2015). There have been many ways reported to prepare xylan-based antimicrobial materials. For example, a novel food preservative was prepared by co-heating xylan with chitosan, and it exhibited excellent antimicrobial activity against E. coli and Staphylococcus aureus (Li et al. 2011). Chitosan- 
xylan/cellulose nanowhiskers (CNW) nanocomposite films with antibacterial and antioxidant properties have successfully been prepared in which CNW was used as nanofillers (Bao et al. 2018). Carboxymethylated xylan was blended with agar (Ag), ammonium zirconium carbonate (AZC), and linoleic acid (LA) to produce edible films with antimicrobial activity (Queirós et al. 2017). Despite these reported efforts, the studies of xylan for high value-added applications are still insufficient. As one of the important subjects, the exploration of possibilities for xylan to be used as antimicrobial additive agent in paper products against $E$. Coli has been the focus of researchers.

Similarly to cellulose, xylan originally does not have antimicrobial activity and requires modification to achieve this property. Polyhexamethylene guanidine hydrochloride $(\mathrm{PHGH})$ is one kind of water-soluble polycation that has antimicrobial activity against both Gram-positive and Gram-negative bacteria, as well as having low mammalian toxicity (Guan et al. 2008). The introduction of PHGH could endow the macromolecule with efficient antimicrobial activity (Guan et al. 2007; Liu et al. 2014), which also offers a potential pathway of endowing xylan with antimicrobial ability against E. coli bacteria.

Therefore, in this work, a new antimicrobial additive agent based on a xylanderivative by graft polymerization of PHGH with xylan was prepared using ceric ammonium nitrate as an initiator. The optimal conditions for xylan derivative preparation were first determined by evaluating the whole preparation process. The obtained xylan derivatives were characterized by structure, thermal stability, and rheological behavior determined by Fourier transform infrared spectroscopy (FTIR), carbon nuclear magnetic resonance spectroscopy $\left({ }^{13} \mathrm{C} \mathrm{NMR}\right)$, thermogravimetric analyser (TGA), elemental analyser (EA), and a rheology meter. Additionally, mechanical properties are also an important aspect for the food-related paper products that need to be studied. Therefore, the antimicrobial activity against $E$. coli of the xylan derivative obtained at the optimal condition as well as its ability as a strengthening agent to improve mechanical properties of paper sheet were systematically investigated. This work found a new way to modify xylan and investigated its applications as a new antimicrobial additive agent against $E$. coli bacteria and as a mechanical enhancing agent for paper products. The obtained antimicrobial additive agent product shows great potential for application in many areas, especially for food-related paper products, such as packaging paper, baking paper, and napkin paper.

\section{EXPERIMENTAL}

\section{Materials}

Xylan $\left(M_{\mathrm{w}} 49000 \mathrm{~g} / \mathrm{mol}\right.$, purity $\left.85 \%\right)$ extracted from sugarcane bagasse was obtained from Shanghai Yuanye Bio-Technology Co., Ltd. (Shanghai, China). Pretreated waste newspaper pulp (mainly American wastepaper) was provided by a local paper company (Guangzhou Paper Group Ltd., Guangzhou, China). Ceric ammonium nitrate (CAN) (99.0\%, Analytical Reagent, AR) was purchased from Tianjin Damao Chemical Reagent Factory (Tianjin, China). The 2,3-epoxypropyltrimethylammonium chloride (ETA) (95\%), hexamethylene diamine (98\%, AR), guanidine hydrochloride (99\%, AR), dimethyl sulfoxide ( $\geq 99 \%$, AR), and glycidyl methacrylate (GMA) (97\%, AR) were purchased from Shanghai Macklin Biochemical Co., Ltd. (Shanghai, China). 
The acetone used in this procedure was purchased from Nanjing Chemical Reagent Co., Ltd. (Nanjing, China). Sodium hydroxide (NaOH) (95\%, AR) and ethanol (99\%, AR) were purchased from Guangzhou Chemical Reagent Factory (Guangzhou, China). Gramnegative bacteria (E. coli, ATCC 25922) were purchased from Shanghai Beinuo BioTechnology Co., Ltd. (Shanghai, China). Chemicals used in this study were all analytical reagent grade and used without any purification. Deionized (DI) water was also used in all experiments. Polyhexamethylene guanidine hydrochloride $(\mathrm{PHGH})$ was prepared by condensation polymerization of hexamethylene diamine and guanidine hydrochloride as described in a previous work (Qian et al. 2011b).

\section{Preparation of cationic-xylan}

Cationic xylan (CX) was prepared based on the procedure described in the authors' previous work with some minor changes (Peng et al. 2012). In summary, a solution of $3 \mathrm{~g}$ xylan in $90 \mathrm{~mL}$ deionized water was prepared in a $250-\mathrm{mL}$ flask and treated with $0.736 \mathrm{~g}$ $\mathrm{NaOH}$ (the molar ratio of $\mathrm{NaOH}$ and the xylose unit in xylan was 0.8 ) was added for alkalization of xylan for $1 \mathrm{~h}$. Afterwards, the flask was placed in a microwave reactor (400 W) (GAS-800; Beijing Xianghu Science and Technology Development Reagent Co., Ltd., Beijing, China) and $20.907 \mathrm{~g}$ ofETA (the molar ratio of ETA and xylose unit in xylan was 6) was added to the flask when the temperature of microwave reactor reached $70{ }^{\circ} \mathrm{C}$. After allowing the reaction to proceed for $40 \mathrm{~min}$, the precipitate was formed in $100 \%$ ethanol and fractionated by filtration with three times the volume of ethanol. The precipitate was washed by filtration again with $70 \%$ ethanol until there was no white precipitate formed in the ethanol filtrates by titration with silver nitrate. The washed precipitate was dissolved in deionized water and dialyzed with membrane of molecular weight cutoff of 3500 in DI water for 5 days until the $\mathrm{pH}$ of the dialyzed liquid became neutral. The CX was finally obtained after drying in a vacuum oven at $50{ }^{\circ} \mathrm{C}$ for $24 \mathrm{~h}$. The degree of substitution (DS) of the prepared CX was 0.38 , which was determined by an elemental analysis method (Peng et al. 2011).

\section{Preparation of cationic-xylan-grafted-PHGH}

Unsaturated double bonds were introduced to PHGH by reacting with GMA, where the molar ratio of amino and epoxy groups was kept at 1.0 (Guan et al. 2007). The reaction was performed at room temperature for $6 \mathrm{~h}$. The obtained products were precipitated and washed with acetone to remove unreacted GMA. The washed products were dissolved in an appropriate amount of methanol, followed by precipitation and washed with acetone again. The same treatment was performed three times, and the final purified GMAmodified PHGH product was obtained after drying in vacuum at $25^{\circ} \mathrm{C}$ for $12 \mathrm{~h}$.

A solution of $0.33 \mathrm{~g} \mathrm{CX}$ in $25 \mathrm{~mL}$ deionized water was prepared in a three-necked round flask $(250 \mathrm{~mL})$ under stirring and purging with nitrogen for 20 min. Then, $5 \mathrm{~mL}$ CAN solution was added to the flask while purging with nitrogen continuously for another 10 min. Subsequently, $10 \mathrm{~mL}$ GMA-modified PHGH was added to the CX solution and stirred with a slow stream of nitrogen for $4 \mathrm{~h}$. The solution was then dialyzed for 3 days, and the CX-grafted-PHGH (CX-g-PHGH) was finally obtained after drying in a vacuum oven at $50{ }^{\circ} \mathrm{C}$ for $24 \mathrm{~h}$. All conditions of preparing the CX-g-PHGH are listed in Table 1. 
Table 1. Influence of the Synthesis Conditions on CX-g-PHGH

\begin{tabular}{|c|c|c|c|c|c|c|}
\hline $\begin{array}{c}\text { Sample } \\
\text { Number }\end{array}$ & $\begin{array}{c}\text { Temperature } \\
\left({ }^{\circ} \mathrm{C}\right)\end{array}$ & $\begin{array}{c}\text { PHGH } \\
\text { Concentration } \\
(\mathrm{mol} / \mathrm{L})\end{array}$ & $\begin{array}{c}\text { Initiator } \\
\text { Concentration } \\
(\mathrm{mmol} / \mathrm{L})\end{array}$ & $\begin{array}{c}\text { Time } \\
(\mathrm{h})\end{array}$ & $\begin{array}{c}\text { Graft } \\
\text { Ratio } \\
(\%)\end{array}$ & $\begin{array}{c}\text { Graft } \\
\text { Efficiency } \\
(\%)\end{array}$ \\
\hline 1 & 60 & 0.039 & 3 & 4 & 15.54 & 52.54 \\
\hline 2 & 60 & 0.039 & 4 & 4 & 18.45 & 58.45 \\
\hline 3 & 60 & 0.039 & 5 & 4 & 16.9 & 56.69 \\
\hline 4 & 60 & 0.039 & 6 & 4 & 15.93 & 53.35 \\
\hline 5 & 60 & 0.020 & 4 & 4 & 7.27 & 56.65 \\
\hline 6 & 60 & 0.078 & 4 & 4 & 16.01 & 53.21 \\
\hline 7 & 60 & 0.117 & 4 & 4 & 15.26 & 40.73 \\
\hline 8 & 60 & 0.156 & 4 & 4 & 15.03 & 36.58 \\
\hline 9 & 50 & 0.039 & 4 & 4 & 15.66 & 49.60 \\
\hline 10 & 70 & 0.039 & 4 & 4 & 16.82 & 53.28 \\
\hline 11 & 80 & 0.039 & 4 & 4 & 16.24 & 51.44 \\
\hline 12 & 60 & 0.039 & 4 & 2 & 13.56 & 50.26 \\
\hline 13 & 60 & 0.039 & 4 & 3 & 14.18 & 53.47 \\
\hline 14 & 60 & 0.039 & 4 & 5 & 17.21 & 57.56 \\
\hline 15 & 60 & 0.039 & 4 & 6 & 16.52 & 55.48 \\
\hline
\end{tabular}

Grafting ratio and efficiency of the as-prepared polymers were determined based on Eqs. 1 and 2, and the mean value of the results obtained from three parallel samples under each condition is reported in Table 1 ,

$$
\begin{aligned}
& \text { Grafting ratio }(\%)=\left(W_{\mathrm{g}}-W_{0}\right) / W_{0} \times 100 \\
& \text { Grafting efficiency }(\%)=\left(W_{\mathrm{g}}-W_{0}\right) / \mathrm{W}_{\mathrm{p}} \times 100
\end{aligned}
$$

where $W_{0}$ is the weight $(\mathrm{g})$ of $\mathrm{CX}, W_{\mathrm{g}}$ is the weight $(\mathrm{g})$ of CX-g-PHGH, and $W_{\mathrm{p}}$ is the weight $(\mathrm{g})$ of functional PHGH.

\section{Methods}

\section{Characterizations of the prepared products}

Xylan, CX, and CX-g-PHGH were dried in an infrared drying oven before characterization for their structures and properties. Fourier transform infrared spectra was obtained with a Fourier transform spectrophotometer (Nicolet 750; ThermoFisher Scientific, Waltham, MA, USA) appended with an attenuated total reflectance (ATR) technique. A total of 32 scans were accumulated in the transmission mode with a resolution of $4 \mathrm{~cm}^{-1}$. The spectrum was obtained from a range of $4000 \mathrm{~cm}^{-1}$ to $400 \mathrm{~cm}^{-1}$.

The solution-state ${ }^{13} \mathrm{C}-\mathrm{NMR}$ spectra were recorded on a Bruker DRX-400 spectrometer (Bruker, Karlsruhe, Germany) at $25^{\circ} \mathrm{C}$ after 15000 scans. The sample (80 $\mathrm{mg}$ ) was dissolved in $1 \mathrm{~mL} \mathrm{D}_{2} \mathrm{O}$. The running parameters were: $30^{\circ}$ pulse flipping angle, $9.2 \mu \mathrm{s}$ pulse width, and a $1.36 \mathrm{~s}$ acquisition time with $2 \mathrm{~s}$ relaxation delay.

Elemental analysis (EA) is for the quantitative determination of specific elements of the samples. Specimens weighing approximately $3 \mathrm{mg}$ to $5 \mathrm{mg}$ were heated in a Vario EL elemental analyzer (Elementar, Langenselbold, Germany) under an oxygen atmosphere, and elements of $\mathrm{C}, \mathrm{H}$, and $\mathrm{N}$ in xylan, $\mathrm{CX}$, and $\mathrm{CX}$-g-PHGH were determined.

The molecular weights of xylan, CX and CX-g-PHGH were determined by GPC on a PL Aquagel-OH 60 column $(300 \mathrm{~mm} \times 7.5 \mathrm{~mm}$; Agilent Technologies, Santa Clara, 
CA, USA) and calibrated with PL pullulan polysaccharide standard (average peak molecular weights of 783, 12200, 100000, and $1600000 \mathrm{~g} / \mathrm{mol}$ ). A flow rate of $0.5 \mathrm{~mL} / \mathrm{min}$ was maintained with ultrapure water as an eluent. Samples were dissolved in ultrapure water to reach a concentration of $0.1 \%$ before characterization.

Dynamic rheological properties of $\mathrm{CX}$ and $\mathrm{CX}-\mathrm{g}-\mathrm{PHGH}$ were determined using a sandwich rheometer (AR2000; TA Instruments, New Castle, DE, USA). All samples were dissolved in water with a magnetic stirrer for $30 \mathrm{~min}$ to form stable solutions. The solutions were then dropped on a Brookfield D VIII instrument panel (LabX, Midland, Canada). Software (Rheo 2000, Brookfield D VIII, LabX) provided by the manufacturer with the instrument was used to set up the parameter, to perform rheometer control, and to collect the data. The data for the shear rate, frequency, viscosities, storage modulus $(\underline{G})$, and the loss modulus ( $G$ ") of all samples were collected.

Thermal stability analysis was used to determine thermodynamic properties of xylan, CX, and CX-g-PHGH. The analysis was performed using thermogravimetric analysis (TGA) and differential thermal analysis (DTA) on a simultaneous thermalgravimetric analyzer (TGA Q500; TA Instruments, New Castle, DE, USA). Approximately $5 \mathrm{mg}$ samples were heated to $700{ }^{\circ} \mathrm{C}$ from room temperature with the heating rate of $10^{\circ} \mathrm{C} / \mathrm{min}$ in a nitrogen atmosphere.

\section{Preparation and mechanical properties tests of CX-g-PHGH paper sheets}

Five sheets with grammage (weight per unit area) of approximately $55 \mathrm{~g} / \mathrm{m}^{2}$ were prepared based on norm GB/T 2828 (1981) (Ren et al. 2009a). The addition amount of CXg-PHGH was $0.3 \%$ to $1.5 \%$ based on the oven-dried weight of waste newspaper pulp. Briefly, CX-g-PHGH and the waste newspaper pulp were homogenized under stirring for $10 \mathrm{~min}$ before forming paper sheets. The sheets were formed via a fast papermaking machine (MESSMER 255; Testing Machines, Inc., New Castle, DE, USA) and dried. The obtained sheets were cut to shape and placed in a controlled humidity room to condition at $25{ }^{\circ} \mathrm{C}$ for $24 \mathrm{~h}$ before mechanical tests. As a comparison, CX paper sheets were also produced via the same preparation process. The GB/T 22865 (2008) standard was applied for the mechanical testing of the sheets (Chen et al. 1990). The tests were conducted 10 times for each sample, and the mean value of the mechanical tests was reported in this work.

\section{Antimicrobial tests of the xylan derivatives}

The antimicrobial activity was tested against Gram-negative bacteria (E. coli, ATCC 25922). The E. coli bacteria were cultured and grown in Luria Bertani (LB) liquid medium $(10 \mathrm{~g} / \mathrm{L}$ peptone, $5 \mathrm{~g} / \mathrm{L}$ yeast extract, $10 \mathrm{~g} / \mathrm{L} \mathrm{NaCl}$, and at $\mathrm{pH} 7.0)$ for $12 \mathrm{~h}$ at $37^{\circ} \mathrm{C}$. The bacteria were further diluted with $\mathrm{NaCl}$ solution $(0.85 \%, \mathrm{w} / \mathrm{v})$ to obtain a concentration of approximately $10^{5} \mathrm{CFU} / \mathrm{mL}$. The diluted suspensions $(0.1 \mathrm{~mL})$ of $E$. coli were then distributed homogeneously onto the LB agar medium $(10 \mathrm{~g} / \mathrm{L}$ peptone, $5 \mathrm{~g} / \mathrm{L}$ yeast extract, $10 \mathrm{~g} / \mathrm{L} \mathrm{NaCl}$, and $15 \mathrm{~g} / \mathrm{L}$ agar).

The obtained paper sheets with xylan derivatives with a diameter of $6 \mathrm{~mm}$ were prepared and placed in the plate culture medium that was coated with the bacterial suspension. The antimicrobial ability of the xylan derivatives was evaluated by measuring the diameter of the inhibition zones for E. coli on the paper sheets. 


\section{RESULTS AND DISCUSSION}

\section{Synthesis Determination of CX-g-PHGH}

The $\mathrm{Ce}^{4+}$ in ceric ammonium nitrate has the ability to attack and convert the hydroxyl groups of CX to free radicals, which could have activity to further react with modified PHGH and form CX-g-PHGH (Raj et al. 2010). The synthesis procedure is proposed in Scheme I.

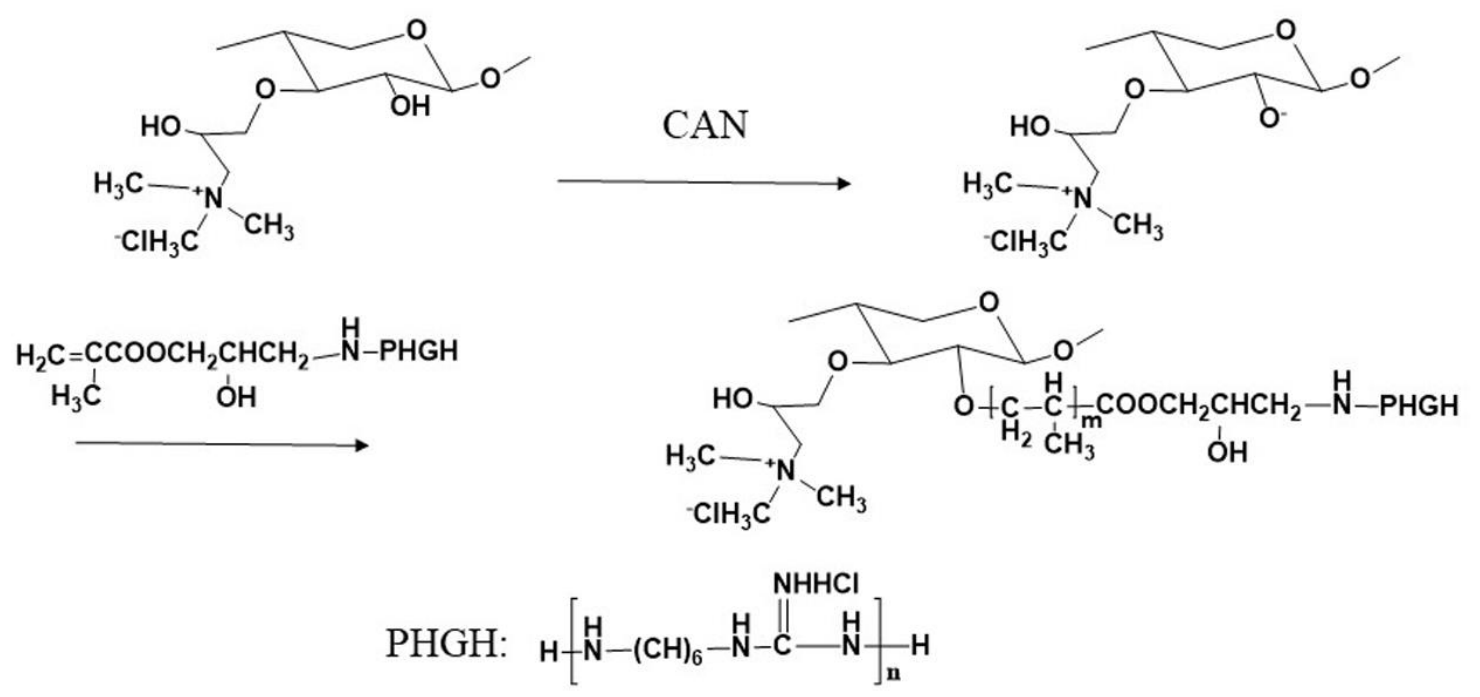

Scheme I. Copolymerization of PHGH onto CX

There are many factors in the reaction, such as the concentration of initiator, the amount of PHGH added, the reaction temperature, and the total reaction time, that could clearly affect the grafting ratio and grafting efficiency of the final products. The influences of initiator concentration on grafting ratio and grafting efficiency of the CX-g-PHGH are shown in Fig. 1a, and detailed values are shown in Table 1.

As shown, the grafting ratio and efficiency increased drastically with the increase of the initiator concentration until $4 \mathrm{mmol} / \mathrm{L}$, with the values increasing to approximately $18.4 \%$ and $58.4 \%$ for grafting ratio and efficiency, respectively. However, when an initiator concentration higher than $4 \mathrm{mmol} / \mathrm{L}$ was applied, both the grafting ratio and efficiency decreased. This phenomenon was in accordance to previous findings by Qian et al. (2008), which was probably because the excess initiator started to participate in the termination step of the growing chains and subsequently initiated the homopolymerization of PHGH.

The influence of the PHGH concentration on the grafting ratio and grafting efficiency is shown in Fig. 1b. It is clear that the grafting ratio and the efficiency increased sharply up to $18.4 \%$ and $58.4 \%$, respectively, when the PHGH concentration was lower than $0.04 \mathrm{~mol} / \mathrm{L}$. However, afterwards, the grafting ratio and efficiency decreased rapidly, which was probably caused by the self-polymerization resulting from high PHGH concentration (Guan et al. 2008).

The increase of reaction temperature may lead to multiple possible outcomes, including increasing the diffusion of $\mathrm{CX}$ and $\mathrm{PHGH}$, facilitating redox initiator system, and enhancing the chain propagation, but likely increasing the rate of termination and homopolymerization in bulk phase (Singh et al. 2004; Wang and $\mathrm{Xu}$ 2006). Therefore, when the temperature was lower than $60{ }^{\circ} \mathrm{C}$, there was a sharp increase for both grafting 
ratio and efficiency that reached maximum values of $18.4 \%$ and $58.4 \%$, respectively (Fig. 1c). However, the grafting ratio and efficiency decreased when the reaction temperature was higher than $60^{\circ} \mathrm{C}$, which was due to the domination of homopolymerization caused by high temperature.

(a)

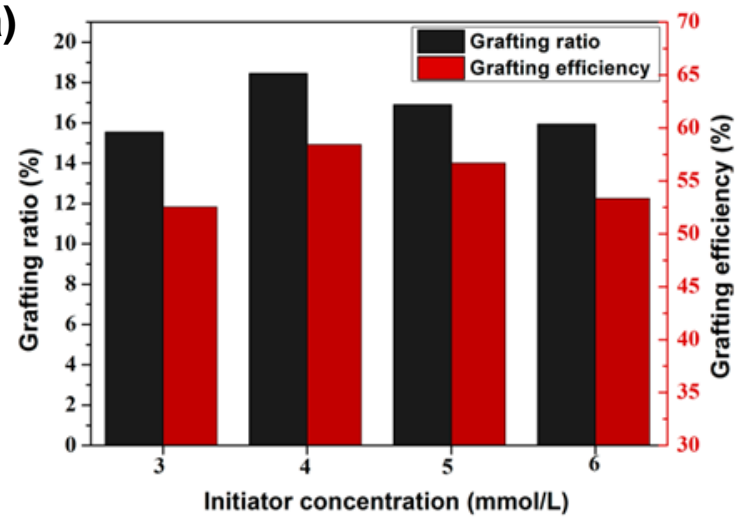

(c)

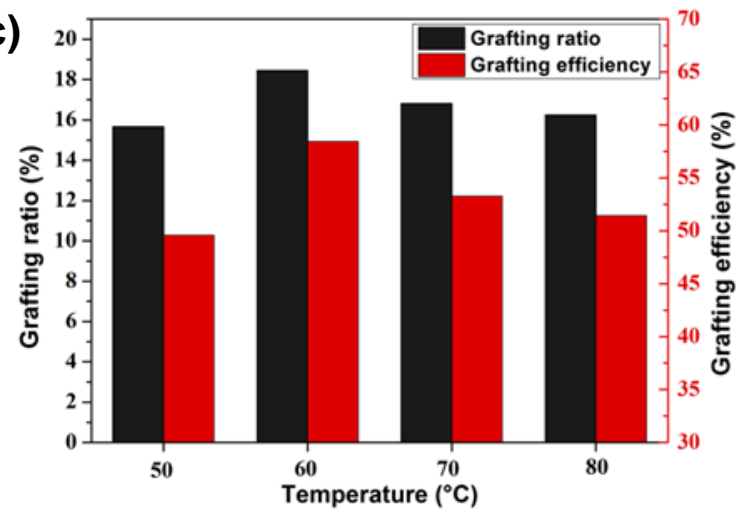

(b)

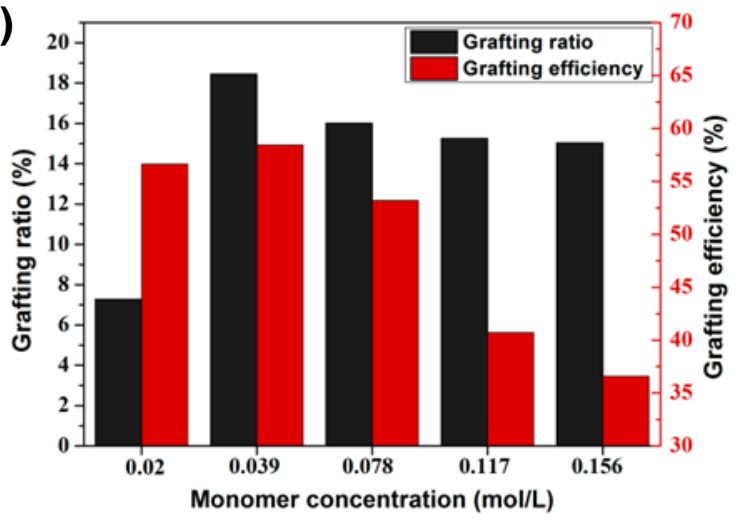

(d)

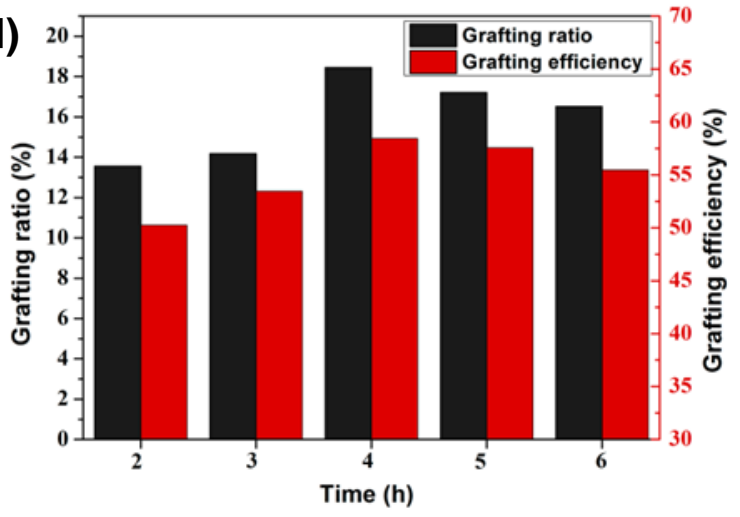

Fig. 1. Influences of conditions on grafting ratio and efficiency of $\mathrm{CX}-\mathrm{g}-\mathrm{PHGH}$ : a) initiator concentration, b) PHGH concentration, c) temperature, and d) time

Furthermore, the reaction time also had an important impact on the grafting ratio and efficiency of CX-g-PHGH, as shown in Fig. 1d. When the reaction time increased, the grafting ratio and the efficiency initially increased and then decreased. A reaction time of $4 \mathrm{~h}$ was determined as the optimal time for the grafting ratio and efficiency with maximum values of $18.4 \%$ and $58.4 \%$, respectively. This was explained by the decrease of the PHGH concentration and free radicals in the system as the reaction time increased. This resulted in the leveling-off of the grafting ratio and efficiency (Xu et al. 2017).

It can be concluded from above that the optimal conditions for preparing $\mathrm{CX}-\mathrm{g}$ PHGH were: an initiator concentration of $4 \mathrm{mmol} / \mathrm{L}$, a PHGH concentration of $0.039 \mathrm{~mol} / \mathrm{L}$, a reaction temperature of $60{ }^{\circ} \mathrm{C}$, and a reaction time of $4 \mathrm{~h}$. Therefore, in the following studies, the CX-g-PHGH (sample number 2, as CX-g-PHGH-1) obtained at the optimal condition with maximal grafting ratio of $18.45 \%$ was used for characterization and testing.

\section{FTIR Spectra}

To confirm the successful grafting of PHGH on CX, several analyses, including FTIR, ${ }^{13} \mathrm{C}$-NMR, elemental analysis, and average molecular weight, were performed.

The FTIR spectra of xylan, CX, and CX-g-PHGH-1 are illustrated in Fig. 2. The signals at $3433 \mathrm{~cm}^{-1}, 2918 \mathrm{~cm}^{-1}, 1637 \mathrm{~cm}^{-1}, 1464 \mathrm{~cm}^{-1}, 1033 \mathrm{~cm}^{-1}$, and $897 \mathrm{~cm}^{-1}$ in the 
spectrum represent the transmittance peaks of molecular bonds for xylan. The transmittance band at $2918 \mathrm{~cm}^{-1}$ was assigned to the $\mathrm{C}-\mathrm{H}$ stretching vibration of alkane in xylan. The transmittance peak of $1044 \mathrm{~cm}^{-1}$ is ascribed to the $\mathrm{C}-\mathrm{O}-\mathrm{C}$ stretching of the ether groups (Peng et al. 2012).

(a)

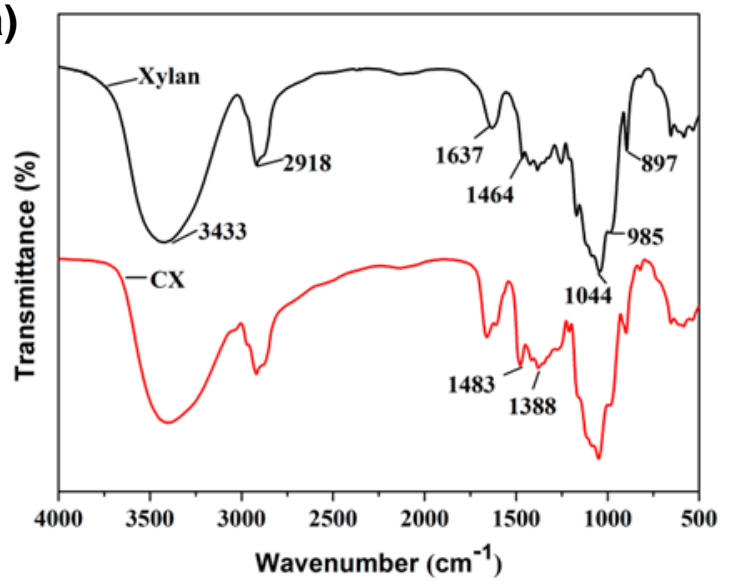

(b)

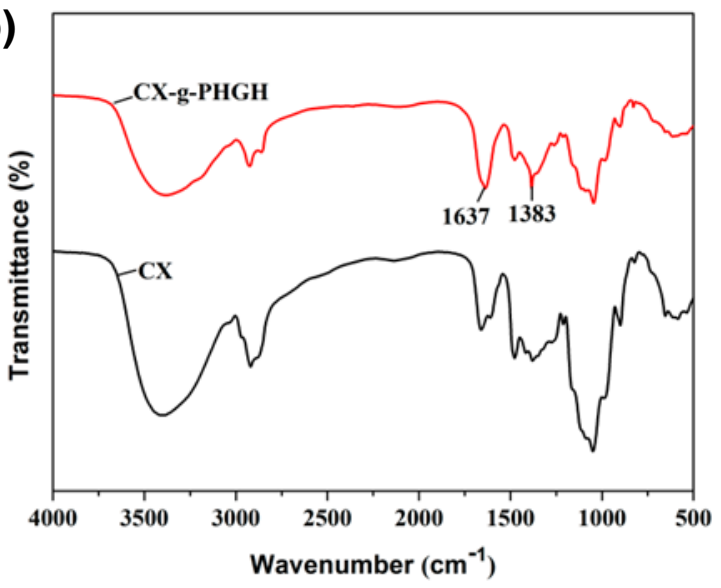

Fig. 2. FTIR spectra of xylan and CX (a) and CX and CX-g-PHGH-1 (b)

As can be seen in Fig. 2a, in the FTIR spectra of CX, an increase in the transmittance intensity of ether bond at $1044 \mathrm{~cm}^{-1}$ was found compared to the spectrum of xylan, indicating that more ether bonds were introduced to the xylan. The transmittance intensity around $1388 \mathrm{~cm}^{-1}$ increased due to the stretching vibration of $\mathrm{C}-\mathrm{N}$. The stretching vibrations of $-\mathrm{CH}_{2}$ and $-\mathrm{CH}_{3}$ on the quaternary ammonium group increased the intensity of the transmittance at $1483 \mathrm{~cm}^{-1}$. These changes in the transmittance peaks indicate that cationic groups were successfully introduced to xylan (Kong et al. 2014).

In Fig. 2b, compared with the spectrum of CX, an increase in the intensities of transmittance at $1383 \mathrm{~cm}^{-1}$ and $1637 \mathrm{~cm}^{-1}$ was seen in the FTIR spectra of CX-g-PHGH, corresponding to the stretching vibration transmittance peaks of $\mathrm{C}-\mathrm{N}$ and $\mathrm{C}=\mathrm{N}$, respectively, which confirmed the successful introduction of PHGH to CX (Guan et al. 2007).

\section{${ }^{13} \mathrm{C}$-NMR Spectra}

The molecular structures of xylan, $\mathrm{CX}$, and $\mathrm{CX}$-g-PHGH-1 were further characterized by ${ }^{13} \mathrm{C}$-NMR (Fig. 3). In the spectrum of xylan (Fig. 3a), the main $(1 \rightarrow 4)$ linked $\beta$-D-xylp units were characterized by the signals at $\delta$ of $102 \mathrm{ppm}, 77.9 \mathrm{ppm}, 76.4$ ppm, 75.9 ppm, and $63.1 \mathrm{ppm}$, which are attributed to C-1, C-4, C-3, C-2, and C-5 of $\beta$-Dxylopyranosyl units, respectively (Kong et al. 2014).

Compared to the ${ }^{13} \mathrm{C}$-NMR spectrum of xylan, the spectrum of the CX (Fig. 3b) had great changes in both intensity and position of the strong signals. The most intense signal appeared at $54.1 \mathrm{ppm}$, which is assigned to carbons of the quaternary ammonium moiety, and the signal at $68.1 \mathrm{ppm}$ is attributed to the $-\mathrm{CH}_{2-}$ (Katsura et al. 1992). This demonstrated that the cationic groups were introduced successfully onto the xylan. In the ${ }^{13} \mathrm{C}-\mathrm{NMR}$ spectrum of CX-g-PHGH-1 (Fig. 3c), some new peaks appeared in comparison with CX. The peaks at $28.0 \mathrm{ppm}, 41.1 \mathrm{ppm}$, and $168 \mathrm{ppm}$ are attributed to the signal peaks of $-\mathrm{CH}_{2-}, \mathrm{C}-\mathrm{N}$, and the ester group carbon (Tanodekaew and Channasanon 2006), respectively, which indicated that PHGH was grafted onto CX successfully. 


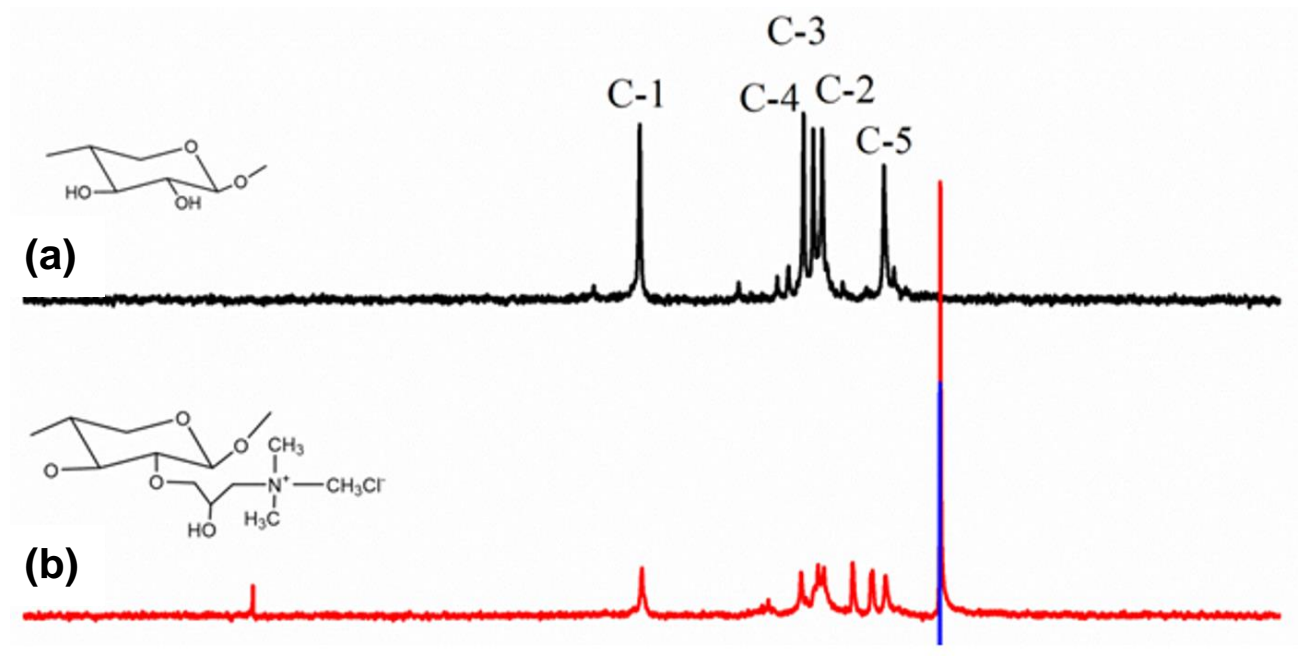

Fig. 3. ${ }^{13} \mathrm{C}-\mathrm{NMR}$ spectra of a) xylan, b) $\mathrm{CX}$, and c) CX-g-PHGH-1

\section{Elemental Analysis}

The element analysis of xylan, CX, and CX-g-PHGH-1 are shown in Table 2. The contents $\mathrm{C}, \mathrm{H}$, and $\mathrm{N}$ in xylan were $40.36 \%, 6.91 \%$, and $0.00 \%$, respectively, while they became $40.36 \%, 7.43 \%$, and $2.16 \%$ after the cationic modification of xylan, indicating that cationic groups were grafted onto xylan.

Table 2. Elemental Analysis of Xylan, CX, and CX-g-PHGH-1

\begin{tabular}{|c|c|c|c|}
\hline Sample & $\mathrm{C}(\%)$ & $\mathrm{H}(\%)$ & $\mathrm{N}(\%)$ \\
\hline Xylan & 40.36 & 6.91 & 0 \\
\hline CX & 40.36 & 7.43 & 2.16 \\
\hline CX-g-PHGH & 40.88 & 7.79 & 9.46 \\
\hline
\end{tabular}

Furthermore, the contents of $\mathrm{C}, \mathrm{H}$, and $\mathrm{N}$ in CX-g-PHGH-1 were $40.88 \%, 7.79 \%$, and $9.46 \%$, respectively. The increase in the $\mathrm{N}$ content confirmed the presence of nitrogenous compounds (PHGH) in $\mathrm{CX}-\mathrm{g}-\mathrm{PHGH}-1$.

\section{Average Molecular Weight}

Average molecular weight is also a promising factor that can confirm the successful conversion of xylan into its derivatives. The molecular weight and molecular weight distribution of xylan, CX, and CX-g-PHGH-1 are shown in Table 3.

Table 3. Molecular Weight and Molecular Weight Distribution of Xylan, CX, and CX-g-PHGH-1

\begin{tabular}{|c|c|c|}
\hline Sample & $M_{\mathrm{w}}(\mathrm{g} / \mathrm{mol})$ & $M_{\mathrm{w}} / M_{\mathrm{m}}$ \\
\hline xylan & 49000 & 4.59 \\
\hline CX & 37500 & 1.99 \\
\hline CX-g-PHGH-1 & 1477129 & 1.15 \\
\hline
\end{tabular}

As shown, the molecular weight of CX was lower than that of xylan, which was probably caused by the degradation of xylan during chemical reaction under alkaline 
conditions. As expected, the molecular weight of CX-g-PHGH-1 was higher, approximately 30 to 40 times than that of xylan and CX, which indicated the successful copolymerization of xylan and CX with PHGH. In addition, the CX and CX-g-PHGH-1 had a relatively low index of polydispersity (1.14 to 1.99) in comparison to xylan (4.59), which indicated that the molecular chain length distribution of CX and CX-g-PHGH-1 was more uniform than that of xylan.

\section{Rheological Properties}

Properties of xylan, CX, and CX-g-PHGH-1, as well as their influence on paper products were tested to fulfill the requirements to be used as an additive agent for antimicrobial paper products.

The tests of rheological behavior for xylan, CX, and CX-g-PHGH-1 would provide better insight into the physico-chemical properties of the polymers and, consequently, to discover their potential applications, e.g., as a coating additive agent to paper products. The rheological behaviors of xylan, CX, and CX-g-PHGH-1 are shown in Figs. 4 and 5.
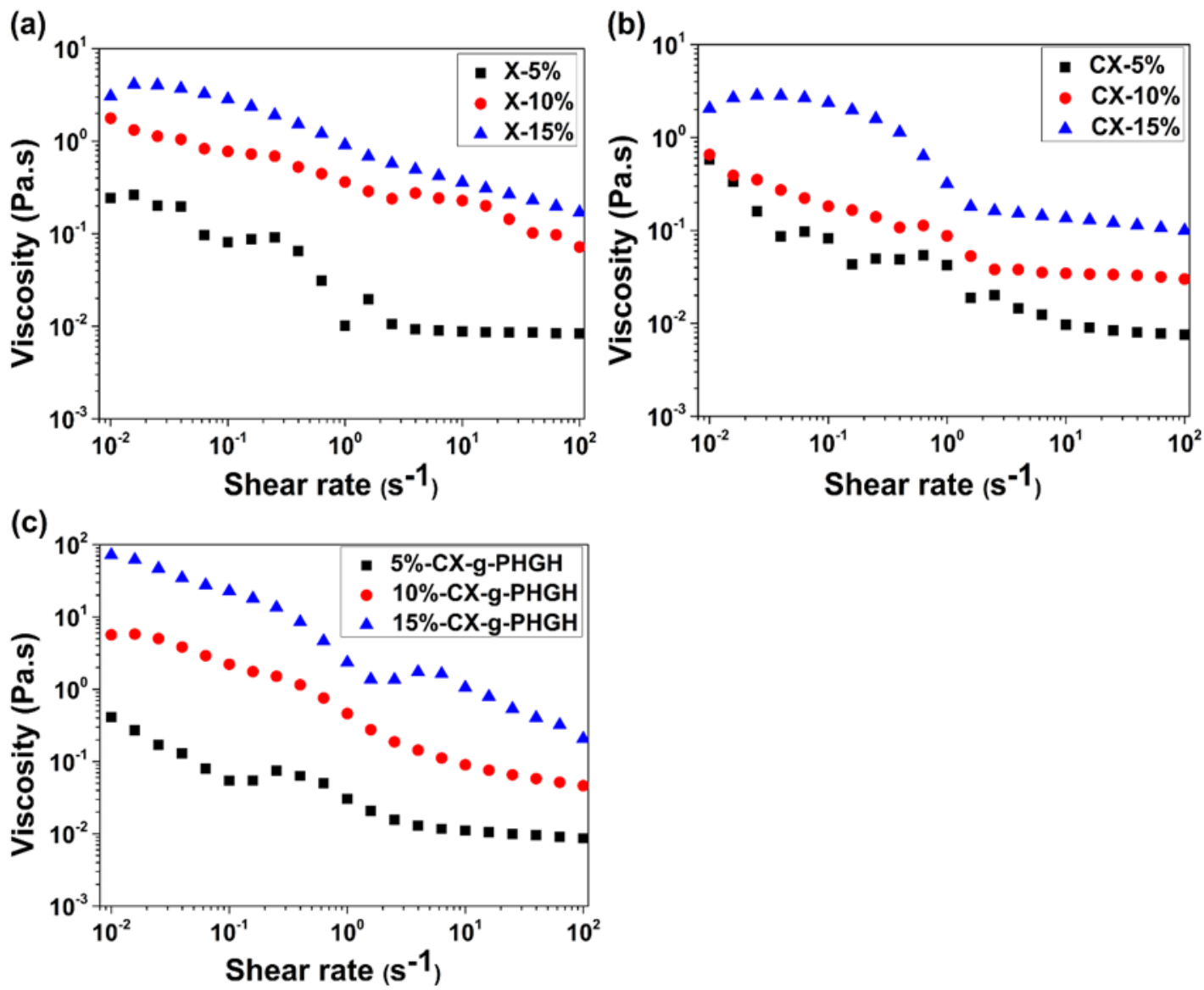

Fig. 4. Shear rate dependence of viscosity for (a) xylan, (b) CX, and (c) CX-g-PHGH-1 at different concentrations

As shown in Fig. 4, the viscosities of xylan, CX, and CX-g-PHGH-1 all decreased with the increase of shear rate. In other words, they exhibited pseudoplastic or shearthinning behavior of these solutions in the range of shear rates tested, which was due to the damage to the network structure of xylan and its derivatives (Peng et al. 2011). 
Accordingly, with a certain additive speed, the xylan, CX, and CX-g-PHGH-1 would be easily applied as a coating agent on the surface of materials such as paper products. Furthermore, the viscosity of the CX-g-PHGH-1 solution was higher than that of the xylan and CX solutions across the whole shear rates range when the concentrations were $5 \%$ and $10 \%$ as well as for shear rates higher than $10 \mathrm{~s}^{-1}$ when the concentration was $15 \%$. This could suggest that CX-g-PHGH-1 solution had stronger intermolecular interactions than the other two solutions (Eutamene et al. 2010).

(a)

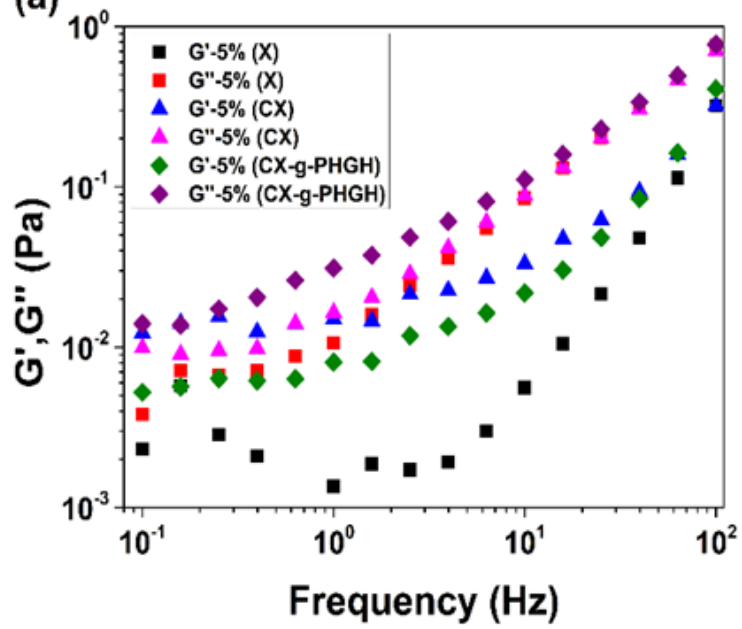

(b)

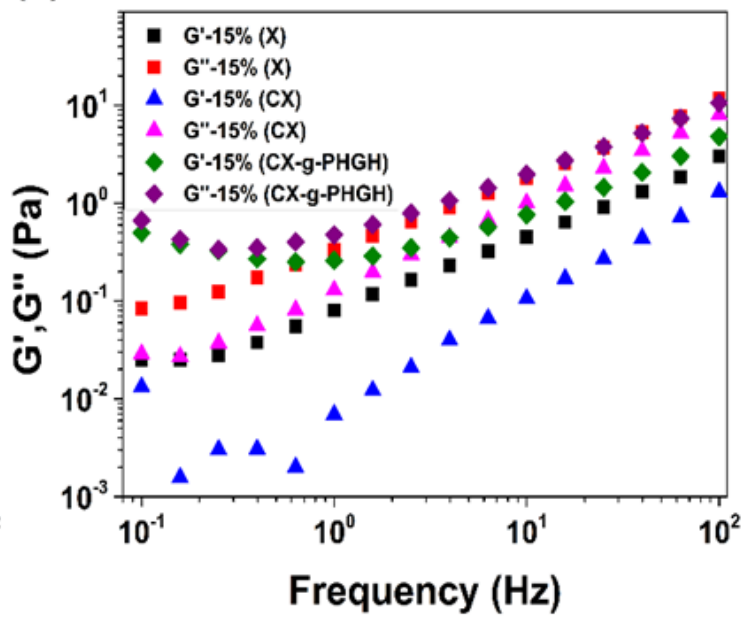

Fig. 5. Frequency dependent modulus of the solutions of xylan (X), CX, and CX-g-PHGH-1 (a) at $5 \%$ concentration and (b) at $15 \%$ concentration

In Fig. 5, the rheological properties (storage modulus $G$ ' and loss modulus $G$ ') of xylan, CX, and CX-g-PHGH-1 are illustrated. When the concentration was 5\%, the storage modulus in the whole frequency region of the xylan and CX-g-PHGH-1 solutions was lower than the loss modulus, demonstrating a viscous behavior. For the CX solution with a concentration of $5 \%$ in the range of $10^{-1}$ to $10^{0} \mathrm{~Hz}$, the storage modulus was higher than the loss modulus, showing stronger elastic properties due to stronger molecular entanglement of CX than that of xylan and CX-g-PHGH-1 (Peng et al. 2011). When the concentration of the solution was $15 \%$, all storage moduli of the xylan, CX, and CX-gPHGH-1 in the whole frequency region were lower than those of the loss moduli, demonstrating viscous behavior. In addition, when the concentration of the solution was $15 \%$, the storage and loss modulus of CX-g-PHGH-1 were higher than the modulus of xylan and $\mathrm{CX}$, indicating a greater viscosity behavior for $\mathrm{CX}-\mathrm{g}-\mathrm{PHGH}-1$ than xylan and CX.

These results can be explained by the influence of molecular weight and functional groups of the macromolecule chains (Peng et al. 2011). Higher molecular weight and the guanidine group caused more chain segments needed for the movement of the viscous flow, thus increasing the frictional resistance and producing a greater viscous behavior. In contrast, a lower molecular weight as well as the cationic groups on the polymer chain may reduce or prevent the associative interactions among themselves in solution, and thus could change the dynamic shear rheological properties of CX (Yoo et al. 2005). The studies above not only further confirmed the successful grafting of PHGH to xylan, but they also 
indicated that the xylan derivative obtained in this work is a promising candidate as a coating additive agent that can be applied to paper products.

\section{Thermal Stability Analysis}

The thermal stability analysis of the samples could facilitate the application of xylan derivative in more scopes. The typical TGA/DTA curves of xylan, CX, and CX-gPHGH-1 are displayed in Fig. 6. There was a substantial weight loss starting at $200{ }^{\circ} \mathrm{C}$ that corresponded to the evaporation of water from the samples.

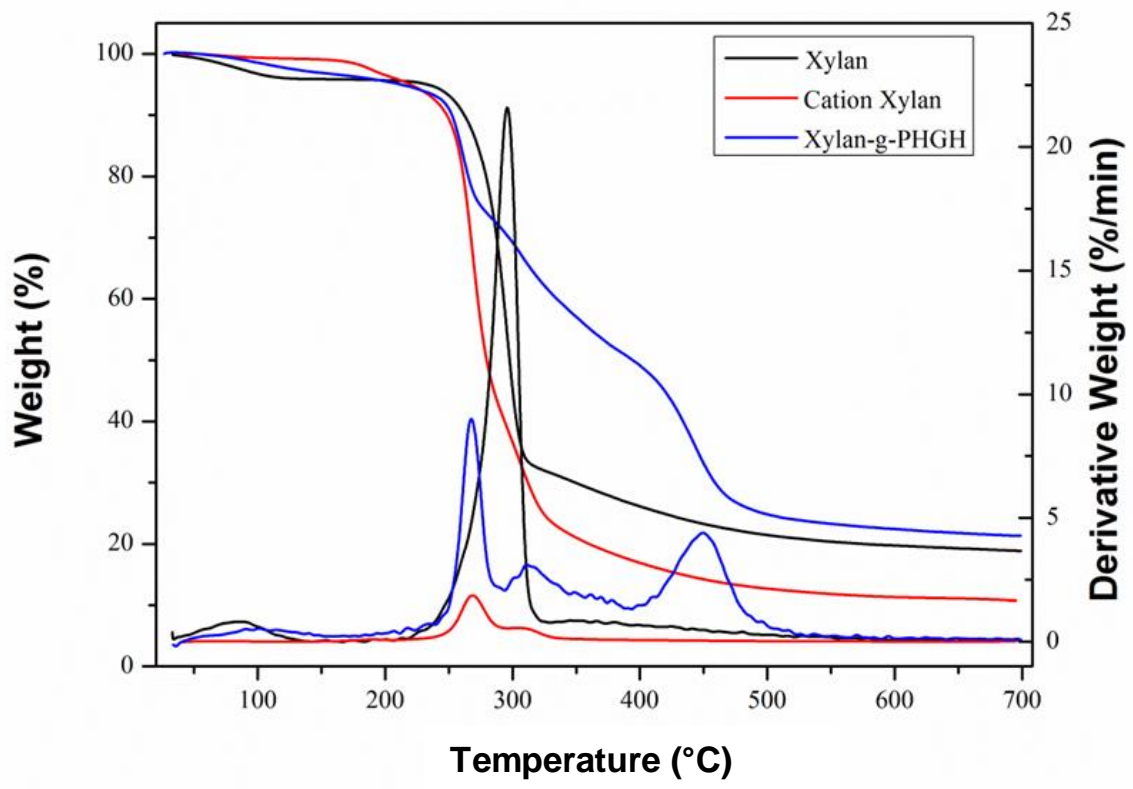

Fig. 6. The TGA/DTA curves of xylan, $\mathrm{CX}$, and CX-g-PHGH-1

The substantial weight loss of xylan occurred at $250{ }^{\circ} \mathrm{C}$ to $320^{\circ} \mathrm{C}$, which could be attributed to backbone scission and following fragmentation of the xylan (Tanodekaew and Channasanon 2006). The CX exhibited a similar thermal stability pattern to that of xylan, but its decomposition temperature was lower, indicating that $\mathrm{CX}$ was more unstable than xylan. This is because the hydrogen bonds and molecular structure are destroyed to a certain extent after cationization, and the grafted cationic groups are not stable (Peng et al. 2012; Xu et al. 2017). Similar to the TGA curves of xylan and CX, there was also a slight loss below $200{ }^{\circ} \mathrm{C}$ for the $\mathrm{CX}-\mathrm{g}-\mathrm{PHGH}-1$ that was attributed to surface water evaporation. A substantial weight loss of CX-g-PHGH-1 was found in the range of $230{ }^{\circ} \mathrm{C}$ to $320^{\circ} \mathrm{C}$, which was due to the thermal decomposition of the xylan. A substantial weight loss of CXg-PHGH-1 also occurred in the range of $320{ }^{\circ} \mathrm{C}$ to $470{ }^{\circ} \mathrm{C}$, which was attributed to the thermal decomposition of PHGH. Above $470{ }^{\circ} \mathrm{C}$, the polymer began to carbonize and the weight of solid matter became constant (Maschio et al. 1992). In summary, the derivatization of xylan with PHGH endowed the new xylan derivative with enough thermal stability to allow the material to be used under high temperature conditions, such as the production of paper and container products, baking, and the packaging of hot food. 


\section{Influence of Xylan Derivatives Addition on Mechanical Properties of Paper Sheets}

The mechanical properties of the paper products are important for applications in packaging, baking, and cleaning. The influences of xylan, CX, and CX-g-PHGH-1 addition on the mechanical properties of the paper sheets are shown in Tables 4, 5, and 6.

\section{Table 4. Mechanical Properties of Paper Sheets After Addition of Xylan}

\begin{tabular}{|c|c|c|c|c|}
\hline $\begin{array}{c}\text { Amount of } \\
\text { Xylan }(\mathrm{wt} \%)\end{array}$ & $\begin{array}{c}\text { Tear Index } \\
\left(\mathrm{mN} \cdot \mathrm{m}^{2} / \mathrm{g}\right)\end{array}$ & $\begin{array}{c}\text { Burst Index } \\
\left(\mathrm{kPa} \cdot \mathrm{m}^{2} / \mathrm{g}\right)\end{array}$ & $\begin{array}{c}\text { Tensile Index } \\
(\mathrm{Nm} / \mathrm{g})\end{array}$ & $\begin{array}{c}\text { Fold Endurance } \\
(\text { Times })\end{array}$ \\
\hline 0 & $6.36 \pm 0.41$ & $2.02 \pm 0.11$ & $35.67 \pm 0.92$ & $9 \pm 0.4$ \\
\hline 0.3 & $6.39 \pm 0.50$ & $2.10 \pm 0.14$ & $36.83 \pm 0.73$ & $9 \pm 0.5$ \\
\hline 0.5 & $6.42 \pm 0.45$ & $2.18 \pm 0.15$ & $37.26 \pm 0.56$ & $10 \pm 0.5$ \\
\hline 1.0 & $6.45 \pm 0.62$ & $2.33 \pm 0.15$ & $39.17 \pm 0.62$ & $12 \pm 0.5$ \\
\hline 1.5 & $6.40 \pm 0.55$ & $2.24 \pm 0.16$ & $38.23 \pm 0.72$ & $11 \pm 0.5$ \\
\hline
\end{tabular}

Note: Grammage of each sheet was approximately $55 \mathrm{~g} / \mathrm{m}^{2}$, the stirring time of pulp after addition of xylan was $10 \mathrm{~min}$

As shown in Table 4, the addition of xylan had little effect on the mechanical properties of the paper sheets tested. When the amount of xylan was $1.0 \mathrm{wt} \%$ in the paper sheet, compared to the mechanical properties of the reference paper without xylan, the tensile index, tear index, and burst index increased $9.81 \%, 1.42 \%$, and $15.35 \%$, respectively. Meanwhile, there was also a minor increase for the folding endurance after addition of xylan.

The addition of CX also improved the mechanical properties of the paper sheets but to a larger extent than addition of xylan as shown in Table 5. This was probably because the cationic groups in the CX could absorb the anionic hydroxyl groups $(-\mathrm{OH})$ on the fibers, which could improve the combined interactive forces among fibers, thereby increasing the mechanical properties of sheets (Ren et al. 2009b). Compared to the reference paper sheet, when the amount of CX was $1.0 \mathrm{wt} \%$, the tensile index, tear index, and burst index increased $13.5 \%, 12.0 \%$, and $24.3 \%$, respectively, and folding endurance increased $55.6 \%$. The mechanical properties of the paper sheets became lower when the addition of CX was over $1.0 \mathrm{wt} \%$. This was probably caused by excessive addition of cationic group in CX that prevented hydrogen bonding between cellulose fibers, which correspondingly resulted in the decrease of the paper strength (Liu et al. 2014).

\section{Table 5. Mechanical Properties of Paper Samples After Addition of CX}

\begin{tabular}{|c|c|c|c|c|}
\hline $\begin{array}{c}\text { Amount of } \\
\text { Cationic-xylan } \\
(\mathrm{wt} \%)\end{array}$ & $\begin{array}{c}\text { Tear Index } \\
\left(\mathrm{mN} \cdot \mathrm{m}^{2} / \mathrm{g}\right)\end{array}$ & $\begin{array}{c}\text { Burst Index } \\
\left(\mathrm{kPa} \cdot \mathrm{m}^{2} / \mathrm{g}\right)\end{array}$ & $\begin{array}{c}\text { Tensile Index } \\
(\mathrm{Nm} / \mathrm{g})\end{array}$ & $\begin{array}{c}\text { Fold Endurance } \\
(\text { Times })\end{array}$ \\
\hline 0 & $6.36 \pm 0.43$ & $2.02 \pm 0.10$ & $35.67 \pm 0.89$ & $9 \pm 0.4$ \\
\hline $0.3 \%$ & $6.44 \pm 0.55$ & $2.26 \pm 0.13$ & $37.45 \pm 0.82$ & $9 \pm 0.4$ \\
\hline $0.5 \%$ & $6.65 \pm 0.34$ & $2.38 \pm 0.13$ & $38.89 \pm 0.71$ & $10 \pm 0.5$ \\
\hline $1.0 \%$ & $7.12 \pm 0.52$ & $2.51 \pm 0.21$ & $40.48 \pm 0.74$ & $14 \pm 0.4$ \\
\hline $1.5 \%$ & $6.89 \pm 0.39$ & $2.31 \pm 0.15$ & $39.06 \pm 0.85$ & $12 \pm 0.5$ \\
\hline
\end{tabular}

Note: Grammage of each paper was approximately $55 \mathrm{~g} / \mathrm{m}^{2}$, the stirring time of pulp after addition of CX was $10 \mathrm{~min}$

When CX-g-PHGH was added to the paper sheets, there were obvious improvements to the mechanical properties of the paper sheets that were affected not only by the amount of addition but also the grafting ratios of PHGH (Table 6). 
Table 6. Mechanical Properties of Paper Samples After Addition of CX-g-PHGH

\begin{tabular}{|c|c|c|c|c|c|}
\hline $\begin{array}{c}\text { Grafting Ratio } \\
(\%)\end{array}$ & $\begin{array}{c}\text { Amount of CX- } \\
\mathrm{g}-\mathrm{PHGH}(\mathrm{wt} \%)\end{array}$ & $\begin{array}{c}\text { Tear Index } \\
\left(\mathrm{mN} \cdot \mathrm{m}^{2} / \mathrm{g}\right)\end{array}$ & $\begin{array}{c}\text { Burst Index } \\
\left(\mathrm{kPa} \cdot \mathrm{m}^{2} / \mathrm{g}\right)\end{array}$ & $\begin{array}{c}\text { Tensile Index } \\
(\mathrm{Nm} / \mathrm{g})\end{array}$ & $\begin{array}{c}\text { Fold } \\
\text { Endurance } \\
(\text { Times })\end{array}$ \\
\hline 0 & 0 & $6.36 \pm 0.44$ & $2.02 \pm 0.12$ & $35.67 \pm 0.90$ & $9 \pm 0.4$ \\
\hline 14.27 & 1 & $7.35 \pm 0.31$ & $2.48 \pm 0.13$ & $40.96 \pm 0.75$ & $12 \pm 0.5$ \\
\hline 15.54 & 1 & $7.84 \pm 0.59$ & $2.59 \pm 0.22$ & $41.97 \pm 0.82$ & $15 \pm 0.5$ \\
\hline 16.90 & 1 & $7.73 \pm 0.53$ & $2.60 \pm 0.22$ & $42.00 \pm 0.75$ & $15 \pm 0.6$ \\
\hline 18.45 & 1 & $7.97 \pm 0.50$ & $2.63 \pm 0.16$ & $42.83 \pm 0.95$ & $16 \pm 0.5$ \\
\hline 18.45 & 0.3 & $6.71 \pm 0.52$ & $2.22 \pm 0.18$ & $40.35 \pm 0.93$ & $13 \pm 0.5$ \\
\hline 18.45 & 0.5 & $7.35 \pm 0.31$ & $2.57 \pm 0.12$ & $40.97 \pm 0.85$ & $14 \pm 0.5$ \\
\hline 18.45 & 1.5 & $7.26 \pm 0.33$ & $2.55 \pm 0.15$ & $41.23 \pm 0.81$ & $12 \pm 0.4$ \\
\hline
\end{tabular}

Note: Grammage of each paper was approximately $55 \mathrm{~g} / \mathrm{m}^{2}$, the stirring time of pulp after addition of $\mathrm{CX}-\mathrm{g}-\mathrm{PHGH}-1$ was 10 min.

As shown in Table 6, the higher grafting ratio of CX-g-PHGH resulted in higher mechanical properties of the paper sheet. When CX-g-PHGH-1 (with the highest grafting ratio of $18.45 \%$, obtained at optimal conditions) was added, the index of tensile, tear, burst, and folding endurance increased $20.1 \%, 25.3 \%, 30.2 \%$, and $77.8 \%$, respectively, compared with the reference paper sheet. It is also well known that paper strength is dependent on the fiber strength as well as the hydrogen bonding force among fibers. The PHGH contains guanidine groups with a positive charge that allows the PHGH to adsorb onto the anionic groups on the fibers (Guan et al. 2008). Therefore, the improvements of mechanical properties could be explained by the following: when the CX-g-PHGH was added into the paper pulp, the CX-g-PHGH filled or adhered to the space between the fibers, which resulted in the increase of the bonding point and bonding area between fibers and correspondingly improved the mechanical properties of the sheets (Lima et al. 2003). In addition, the guanidine and cationic groups of CX-g-PHGH adsorbed onto the negatively charged surfaces of the fibers, which resulted in the increase in fiber retention, the improvement in interfiber bonding, and, correspondingly, improved the mechanical properties of the paper sheets (Ren et al. 2009b). The mechanical properties of the paper samples saw improvement as the amount of CX-g-PHGH-1 added increased. However, the mechanical properties of paper began to decrease when the amount of added CX-g-PHGH1 increased over $1.0 \mathrm{wt} \%$. This can be explained by the excessive $\mathrm{NH}_{2}$ brought from CXg-PHGH-1 that prevented hydrogen bonding between the cellulose fibers, which resulted in a decrease of the paper strength (Liu et al. 2014).

\section{Antimicrobial Test of the Paper Sheets with Addition of CX and CX-g-PHGH}

In this work, the antimicrobial activity of the paper sheets with addition of the xylan derivatives was evaluated against $E$. coli bacteria by an inhibition zone method as shown in Fig. 7. As a comparison, the antimicrobial activity tests for the CX-g-PHGH (sample number 1 in Table 1, shown below as CX-g-PHGH-2) obtained with a lower initiator concentration and a lower relative grafting ratio of $15.5 \%$ was also studied.

The inhibition zone method is the most used method for antimicrobial activity testing of materials. Through using this method, the growth of bacteria was inhibited in the formation of transparent circles by the diffusion of antimicrobial agents in agar plates. The antimicrobial ability of the agents was evaluated by the size of the inhibition circle. Guanidino groups of guanidine polymers adsorbed the anions on the cell surface of $E$. Coli bacteria by electrostatic action, which then proceeded to destroy the normal metabolism 
and surface structure of the living bacterial cells, sequentially inhibiting the growth of the bacteria effectively (Qian et al. 2008).

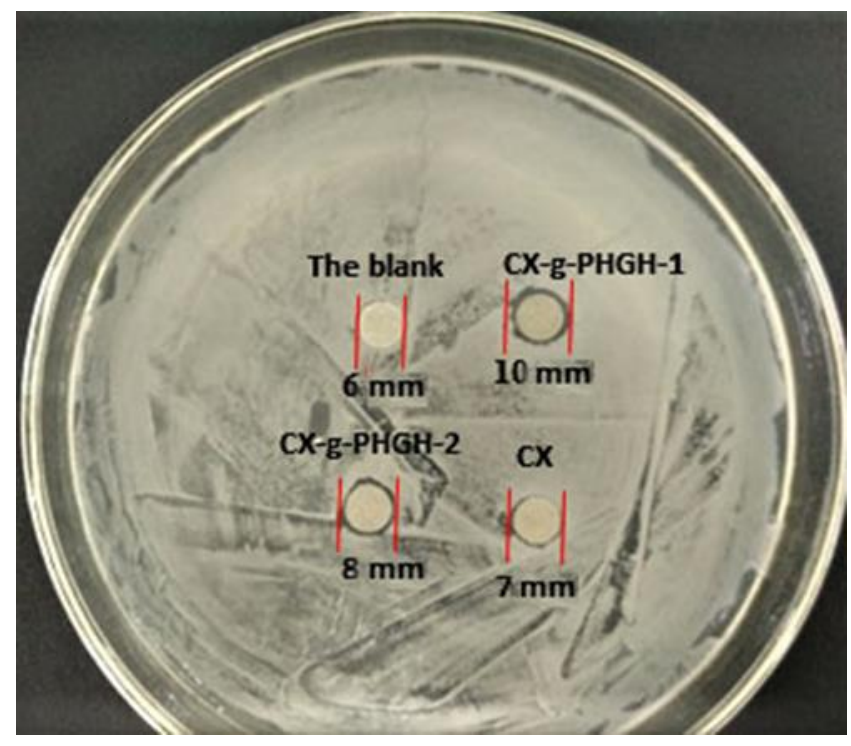

Fig. 7. The antimicrobial activity of the paper samples with the addition of $\mathrm{CX}, \mathrm{CX}-\mathrm{g}-\mathrm{PHGH}-1$, and CX-g-PHGH-2 against E. coli bacteria

Addition of the CX and CX-g-PHGH endowed the paper sheet with antimicrobial properties. The CX paper sample showed weaker antimicrobial ability than the CX-gPHGH samples, exemplified by its smaller inhibition zone diameter of $7 \mathrm{~mm}$. The diameter of the inhibition zone for the paper of CX-g-PHGH-1 (grafting ratio 18.45\%) and CX-gPHGH-2 (grafting ratio 15.54\%) against E. coli enlarged from $6 \mathrm{~mm}$ to 10 and $8 \mathrm{~mm}$ respectively, which suggested that the $\mathrm{CX}-\mathrm{g}-\mathrm{PHGH}$ paper had good antimicrobial activity against $E$. coli and the antimicrobial activity was improved by the increase of $\mathrm{PHGH}$ contents grafted on the CX.

\section{CONCLUSIONS}

1. In the present study, a novel xylan-based antimicrobial additive agent was successfully prepared and applied in cellulosic paper sheets with improved the mechanical properties and antimicrobial activity against E. Coli bacteria. The derived xylan, cationic xylan-grafted-PHGH (CX-g-PHGH), was successfully synthesized by graft copolymerization of cationic xylan (CX) with guanidine polymer (PHGH) using ceric ammonium nitrate (CAN) as an initiator.

2. The optimal reaction parameters to efficiently obtain the $\mathrm{CX}-\mathrm{g}-\mathrm{PHGH}$ were $4 \mathrm{~h}$ at $60^{\circ} \mathrm{C}$ with PHGH concentration of $0.039 \mathrm{~mol} / \mathrm{L}$ and an initiator concentration of $4 \mathrm{mmol} / \mathrm{L}$. At these conditions, the maximum grafting ratio and efficiency of $18.4 \%$ and $58.4 \%$ was reached. Furthermore, the mechanical properties of the paper sheets with added CX-g-PHGH had improvements. Compared to the mechanical properties of a paper sheet without any added xylan derivatives, the addition of CX-g-PHGH improved the mechanical properties of the sheet by up to $20.1 \%$ (tensile index), $25.3 \%$ (tear index), 
$30.2 \%$ (burst index), and $77.8 \%$ (fold endurance). Meanwhile, the paper sheet with addition of CX-g-PHGH exhibited improved viscosity and thermal stability as well as good antimicrobial activity against $E$. Coli bacteria, which was inherited from the antimicrobial activity of the guanidine in $\mathrm{CX}-\mathrm{g}-\mathrm{PHGH}$.

3. The present work found a new way of synthesizing xylan derivatives and used it as an antimicrobial additive agent against $E$. coli bacteria in paper products. The obtained paper product demonstrated highly improved mechanical strength and antimicrobial properties as well as biodegradability and renewable properties that would find great potential in food-related areas, e.g., packaging, baking, and napkin paper, as well as in other areas, such as pharmaceuticals and cosmetics, which expanded the applications of xylan in more highly value-added areas.

\section{ACKNOWLEDGMENTS}

This work was financially supported by the State Key Laboratory of Pulp and Paper Engineering (Grant Nos. 2017C02 and 202011), the Science and Technology Planning Project of Guangdong Province (Grant No. 2017A010103032), the Guangdong Program for Support of Top-notch Young Professionals (Grant No. 2016TQ03Z585), the Fundamental Research Funds for the Central Universities of SCUT (Grant Nos. 2017ZD081 and 2017MS080), the Guangdong Provincial Natural Science Foundation Project (Grant No. 2018A030313211 and 2020A1515010823), and the Guangdong Province Science Foundation for Cultivating National Engineering Research Center for Efficient Utilization of Plant Fibers (Grant No. 2017B090903003).

\section{REFERENCES CITED}

Abreu, A. S., Oliveira, M., Sá, A. D., Rui, M. R., Cerqueira, M. A., Vicente, A. A., and Machado, A. V. (2015). "Antimicrobial nanostructured starch-based films for packaging," Carbohydrate Polymers 129, 127-134. DOI: 10.1016/j.carbpol.2015.04.021

Bao, Y. P., Zhang, H., Luan, Q., Zheng, M. M., Tang, H., and Huang, F. H. (2018). "Fabrication of cellulose nanowhiskers reinforced chitosan-xylan nanocomposite films with antibacterial and antioxidant activities," Carbohydrate Polymers 184, 6673. DOI: 10.1016/j.carbpol.2017.12.051

Chen, P. R., Qu, W. J., and He, F. W. (1990). Pulp and Papermaking Experiment, Light Industry Press, Beijing, China.

Conrad, C. C., Stanford, K., McAllister, T. A., Thomas, J., and Reuter, T. (2014).

"Further development of sample preparation and detection methods for O157 and the top 6 non-O157 STEC serogroups in cattle feces," Journal of Microbiological Methods 105, 22-30. DOI: 10.1016/j.mimet.2014.06.020

Demetrescu, I., Dumitriu, C., Totea, G., Nica, C., Dinischiotu, A., and Ionita, D. (2018). "Zwitterionic cysteine drug coating influence in functionalization of implantable Ti50Zr alloy for antibacterial, biocompatibility and stability properties," Pharmaceutics 10(4), Article Number 220. DOI: 10.3390/pharmaceutics 10040220

Diaz-García, D., Ardiles, P. R., Prashar, S., Rodriguez-Diéguez, A., Páez, P. L., and 
Gómez-Ruiz, S. (2019). "Preparation and study of the antibacterial applications and oxidative stress induction of copper maleamate-functionalized mesoporous silica nanoparticles," Pharmaceutics 11(1), Article Number 30. DOI:

10.3390/pharmaceutics11010030

Dutta, P. K., Tripathi, S., Mehrotra, G. K., and Dutta, J. (2009). "Perspectives for chitosan based antimicrobial films in food applications," Food Chemistry 114(4), 1173-1182. DOI: 10.1016/j.foodchem.2008.11.047

Ebringerová, A., and Heinze, T. (2015). "Xylan and xylan derivatives-biopolymers with valuable properties, 1 - Naturally occurring xylans structures, isolation procedures and properties," Macromolecular Rapid Communications 21(9), 542-556. DOI: 10.1002/1521-3927(20000601)21:9\%3C542::AID-MARC542\%3E3.0.CO;2-7

Eutamene, M., Benbakhti, A., Khodja, M., and Jada, A. (2010). "Preparation and aqueous properties of starch - grafted polyacrylamide copolymers," Starch 61(2), 81-91. DOI: 10.1002/star.200800231

GB/T 22865-2008 (2008). "Kraft," Chinese Technical Association of Pulp and Paper, Beijing, China.

GB/T 2828-81 (1981). "Sampling procedures for inspection by attributes," Chinese Technical Association of Pulp and Paper, Beijing, China.

Goksu, E. I., Karamanlioglu, M., Bakir, U., Yilmaz, L., and Yilmazer, U. (2007). "Production and characterization of films from cotton stalk xylan," Journal of Agricultural Food Chemistry 55(26), 10685-10691. DOI: 10.1021/jf071893i

Guan, Y., Qian, L. Y., Xiao, H. N., and Zheng, A. (2008). "Preparation of novel antimicrobial-modified starch and its adsorption on cellulose fibers: Part I. Optimization of synthetic conditions and antimicrobial activities," Cellulose 15(4), 609-618. DOI: 10.1007/s10570-008-9208-6

Guan, Y., Xiao, H. N., Sullivan, H., and Zheng, A. (2007). “Antimicrobial-modified sulfite pulps prepared by in situ copolymerization," Carbohydrate Polymers 69(4), 688-696. DOI: 10.1016/j.carbpol.2007.02.013

Hansen, N. M. L., and Plackett, D. (2008). "Sustainable films and coatings from hemicelluloses: A review," Biomacromolecules 9(6), 1493-1505. DOI: 10.1021/bm800053z

Horton, D. (1968). Advances in Carbohydrate Chemistry: Volume 21, M. L. Wolfrom, and R. S. Tipson (eds.), Academic Press Inc., New York, NY, USA.

Hromádková, Z., Kováčiková, J., and Ebringerová, A. (1999). "Study of the classical and ultrasound-assisted extraction of the corn cob xylan," Industrial Crops and Products 9(2), 101-109. DOI: 10.1016/s0926-6690(98)00020-x

Kang, Z. Z., Zhang, B., Jiao, Y. C., Xu, Y. H., and He, Q. Z. (2013). "High-efficacy antimicrobial cellulose grafted by a novel quaternarized N-halamine," Cellulose 20(2), 885-893. DOI: 10.1007/s10570-012-9848-4

Karmali, M. A. (2017). "Emerging public health challenges of Shiga toxin-producing Escherichia coli related to changes in the pathogen, the population, and the environment," Clinical Infectious Diseases 64(3), 371-376. DOI: 10.1093/cid/ciw708

Katsura, S., Isogai, A., Onabe, F., and Usuda, M. (1992). "NMR analyses of polysaccharide derivatives containing amine groups," Carbohydrate Polymers 18(4), 283-288. DOI: 10.1016/0144-8617(92)90093-6

Kim, K. S. (2003). "Pathogenesis of bacterial meningitis: From bacteraemia to neuronal injury," Nature Reviews Neuroscience 4, 376-385. DOI: 10.1038/nrn1103

Kong, W. Q., Ren, J. L., Wang, S. Y., Li, M. F., and Sun, R. C. (2014). “A promising 
strategy for preparation of cationic xylan by environment-friendly semi-dry oven process," Fiber and Polymers 15(5), 943-949. DOI: 10.1007/s12221-014-0943-Z

Li, X. X., Shi, X. W., Wang, M., and Du, Y. M. (2011). "Xylan chitosan conjugate-a potential food preservative," Food Chemistry 126(2), 520-525. DOI:

10.1016/j.foodchem.2010.11.037

Lima, D. U., Oliveira, R. C., and Buckeridge, M. S. (2003). "Seed storage hemicelluloses as wet-end additives in papermaking," Carbohydrate Polymers 52, 367-373. DOI: 10.1016/s0144-8617(03)00008-0

Lin, L., Agyemang, K., Abdel-Samie, M. A., and Cui, H. Y. (2019). “Antibacterial mechanism of Tetrapleura tetraptera extract against Escherichia coli and Staphylococcus aureus and its application in pork," Journal of Food Safety 39(6), e12693. DOI: $10.1111 /$ jfs. 12693

Lindblad, M. S., Ranucci, E., and Albertsson, A. C. (2001). "Biodegradable polymers from renewable sources. New hemicellulose-based hydrogels," Macromolecular Rapid Communications 22(12), 962-967. DOI: 10.1002/15213927(20010801)22:12<962::aid-marc962>3.0.co;2-e

Liu, K., Xu, Y. G., Lin, X. X., Chen, L. H., Huang, L. L., Cao, S. L., and Li, J. (2014). "Synergistic effects of guanidine-grafted CMC on enhancing antimicrobial activity and dry strength of paper," Carbohydrate Polymers 110(22), 382-387. DOI: 10.1016/j.carbpol.2014.03.086

Liu, W. T., Lv, Y. J., Yang, R. C., Fu, J. Y., Liu, L., Wang, H., Cao, Q., Tan, C., Chen, H. C., and Wang, X. R. (2018). "New insights into meningitic Escherichia coli infection of brain microvascular endothelial cells from quantitative proteomics analysis," Journal of Neuroinflammation 15, Article Number 291. DOI: 10.1186/s12974-018-1325-z

Manage, D. P., Lauzon, J., Jones, C. M., Ward, P. J., Pilarski, L. M., Pilarski, P. M., and McMullen, L. M. (2019). "Detection of pathogenic Escherichia coli on potentially contaminated beef carcasses using cassette PCR and conventional PCR," BMC Microbiology 19, Article Number 175. DOI: 10.1186/s12866-019-1541-4

Maschio, G., Koufopanos, C., and Lucchesi, A. (1992). "Pyrolysis, a promising route for biomass utilization,” Bioresource Technology 42(3), 219-231. DOI: 10.1016/09608524(92)90025-s

Melosilveira, R. F., Fidelis, G. P., Telles, C. B. S., Dantassantos, N., Elias, S. D. O., Ribeiro, V. B., Barth, A. L., Macedo, A. J., and Leite, E. L. (2011). "In vitro antioxidant, anticoagulant and antimicrobial activity and in inhibition of cancer cell proliferation by xylan extracted from corn cobs," International Journal of Molecular Sciences 13(1), 409-426. DOI: 10.3390/ijms13010409

Peng, X. W., Ren, J. L., and Sun, R. C. (2011). "An efficient method for the synthesis of hemicellulosic derivatives with bifunctional groups in butanol/water medium and their rheological properties," Carbohydrate Polymers 83(4), 1922-1928. DOI: 10.1016/j.carbpol.2010.10.064

Peng, X. W., Ren, J. L., Zhong, L. X., and Sun, R. C. (2012). "Synthesis and characterization of amphoteric xylan-type hemicelluloses by microwave irradiation," Journal of Agricultural Food Chemistry 60(7), 1695-1702. DOI: 10.1021/jf204522k

Petzold, K., Schwikal, K., and Heinze, T. (2006). "Carboxymethyl xylan-synthesis and detailed structure characterization," Carbohydrate Polymers 64(2), 292-298. DOI: 10.1016/j.carbpol.2005.11.037

Poverenov, E., Shemesh, M., Gulino, A., Cristaldi, D. A., Zakin, V., Yefremov, T., and 
Granit, R. (2013). "Durable contact active antimicrobial materials formed by a onestep covalent modification of polyvinyl alcohol, cellulose and glass surfaces," Colloids and Surfaces B: Biointerfaces 112, 356-361. DOI:

10.1016/j.colsurfb.2013.07.032

Pristov, J. B., Mitrović, A., and Spasojević, I. (2011). "A comparative study of antioxidative activities of cell-wall polysaccharides," Carbohydrate Research 346(14), 2255-2259. DOI: 10.1016/j.carres.2011.07.015

Qian, L. Y., Guan, Y., He, B. H., and Xiao, H. N. (2008). "Synergy of wet strength and antimicrobial activity of cellulose paper induced by a novel polymer complex," Materials Letters 62(21-22), 3610-3612. DOI: 10.1016/j.matlet.2008.04.010

Qian, L. Y., Li, X., Sun, S. L., and Xiao, H. N. (2011a). "Preparation of guanidine polymer and its complex as dual-functional agent for cellulose fibre-based hygiene products," Journal of Biobased Materials and Bioenergy 5(2), 219-224. DOI: 10.1166/jbmb.2011.1137

Qian, L. Y., Xiao, H. N., Zhao, G. L., and He, B. H. (2011b). "Synthesis of modified guanidine-based polymers and their antimicrobial activities revealed by AFM and CLSM," ACS Applied Materials \& Interfaces 3(6), 1895-1901. DOI: 10.1021/am200094u

Queirós, L. C. C., Sousa, S. C. L., Duarte, A. F. S., Domingues, F. C., and Ramos, A. M. M. (2017). "Development of carboxymethyl xylan films with functional properties," Journal of Food Science and Technologies 54(1), 9-17. DOI: 10.1007/s13197-0162389-3

Raj, S. B., Kumar, V., and Soni, P. L. (2010). "Ceric ammonium nitrate-initiated graft copolymerization of acrylamide onto Cassia tora gum," Journal of Applied Polymer Science 86(13), 3250-3255. DOI: 10.1002/app.11102

Ren, J. L., Peng, F. and Sun, R. C. (2009a). "The effect of hemicellulosic derivatives on the strength properties of old corrugated container pulp fibres," Journal of Biobased Materials and Bioenergy 3(1), 1-7. DOI: 10.1166/jbmb.2009.1008

Ren, J. L., Peng, F., Sun, R. C., and Kennedy, J. F. (2009b). "Influence of hemicellulosic derivatives on the sulfate kraft pulp strength," Carbohydrate Polymers 75(2), 338342. DOI: 10.1016/j.carbpol.2008.08.011

Ren, J. L., Sun, R. C., Liu, C. F., Cao, Z. N., and Luo, W. (2007). “Acetylation of wheat straw hemicelluloses in ionic liquid using iodine as a catalyst," Carbohydrate Polymers 70(4), 406-414. DOI: 10.1016/j.carbpol.2007.04.022

Ren, J. L., Wang, S. Y., Gao, C. D., Chen, X. F., Li, W. Y., and Peng, F. (2015). " $\mathrm{TiO}_{2-}$ containing PVA/xylan composite films with enhanced mechanical properties, high hydrophobicity and UV shielding performance," Cellulose 22(1), 593-602. DOI: 10.1007/s10570-014-0482-1

Ren, J. L., Xu, F., Sun, R. C., Peng, B., and Sun, J. X. (2008). "Studies of the lauroylation of wheat straw hemicelluloses under heating," Journal of Agricultural Food Chemistry 56(4), 1251-1258. DOI: 10.1021/jf072983q

Schwikal, K., Heinze, T., Ebringerová, A., and Petzold, K. (2005). "Cationic xylan derivatives with high degree of functionalization," Macromolecular Symposium 232(1), 49-56. DOI: 10.1002/masy.200551406

Shaer, A. E., Hanson, P., Worthington, T., Lambert, P., and Mohammed, A. R. (2012). "Preparation and characterization of amino acids-based trimethoprim salts," Pharmaceutics 4(1), 179-196. DOI: 10.3390/pharmaceutics4010179

Singh, V., Tiwari, A., Tripathi, D. N., and Sanghi, R. (2004). "Microwave assisted 
synthesis of Guar-g-polyacrylamide," Carbohydrate Polymers 58(1), 1-6. DOI:

10.1016/j.carbpol.2004.04.010

Sun, R. C. (2010). Cereal Straw as a Resource for Sustainable Biomaterials and Biofuels, Elsevier, Oxford, England.

Sun, S. L., An, Q. Z., Li, X., Qian, L. Y., He, B. H., and Xiao, H. N. (2010). "Synergistic effects of chitosan-guanidine complexes on enhancing antimicrobial activity and wetstrength of paper," Bioresource Technology 101(14), 5693-5700. DOI: 10.1016/j.biortech.2010.02.046

Tanodekaew, S., and Channasanon, S. (2006). "Xylan/polyvinyl alcohol blend and its performance as hydrogel," Journal of Applied Polymer Science 100(3), 1914-1918. DOI: 10.1002/app.22919

Ünlü, C. H., Günister, E., and Atıcı, O. (2009). "Synthesis and characterization of NaMt biocomposites with corn cob xylan in aqueous media," Carbohydrate Polymers 76(4), 585-592. DOI: 10.1016/j.carbpol.2008.11.029

Wang, L. L., and Xu, Y. S. (2006). "Preparation and characterization of graft copolymerization of ethyl acrylate onto hydroxypropyl methylcellulose in aqueous medium," Cellulose 13(2), 191-200. DOI: 10.1007/s10570-005-9043-y

Wang, X., Maruvada, R., Morris, A. J., Liu, J. O., Wolfgang, M. J., Baek, D. J., Bittman, R., and Kim, K. S. (2016). "Sphingosine 1-phosphate activation of EGFR as a novel target for meningitic Escherichia coli penetration of the blood-brain barrier," PLOS Pathogens 12(10), e1005926. DOI: 10.1371/journal.ppat.1005926

Wang, X. Y., Liu, B., Ren, J. L., Liu, C. F., Wang, X. H., Wu, J., and Sun, R. C. (2010). "Preparation and characterization of new quaternized carboxymethyl chitosan/ rectorite nanocomposite," Composites Science and Technology 70(7), 1161-1167. DOI: 10.1016/j.compscitech.2010.03.002

Wu, J., Zheng, Y. D., Song, W. H., Luan, J. B., Wen, X. X., Wu, Z. G., Chen, X. H., Wang, Q., and Guo, S. L. (2014). "In situ synthesis of silver-nanoparticles/bacterial cellulose composites for slow-released antimicrobial wound dressing," Carbohydrate Polymers 102, 762-771. DOI: 10.1016/j.carbpol.2013.10.093

Xu, G. B., Kong, W. Q., Liu, C. F., Sun, R. C., and Ren, J. L. (2017). "Synthesis and characteristic of xylan-grafted-polyacrylamide and application for improving pulp properties," Materials 10(8), 971-982. DOI: 10.3390/ma10080971

Yang, R. C., Qu, X. Y., Xiao, S. Y., Li, L., Xu, B. J., Fu, J. Y., Lv, Y.J., Amjad, N., Tan, C., Kim, K. S., et al. (2019). "Meningitic Escherichia coli-induced upregulation of PDGF-B and ICAM-1 aggravates blood-brain barrier disruption and neuroinflammatory response," Journal of Neuroinflammation 16, Article Number 101. DOI: $10.1186 / \mathrm{s} 12974-019-1497-1$

Yoo, D., Kim, C., and Yoo, B. (2005). "Steady and dynamic shear rheology of rice starch-galactomannan mixtures," Starch 57(7), 310-318. DOI: 10.1002/star.200400390

Zyl, C. V., Prior, B. A., and Preez, J. C. D. (1988). "Production of ethanol from sugar cane bagasse hemicellulose hydrolyzate by Pichia stipites," Applied Biochemistry and Biotechnology 17(3), 357-369. DOI: 10.1007/BF02779170

Article submitted Nov. 11, 2019; Peer review completed: April 25, 2020; Revised version received and accepted: May 1, 2020; Published: May 7, 2020.

DOI: 10.15376/biores.15.3.4781-4801 